\title{
Peroxisomes and Kidney Injury
}

\author{
Radovan Vasko
}

\begin{abstract}
Significance: Peroxisomes are organelles present in most eukaryotic cells. The organs with the highest density of peroxisomes are the liver and kidneys. Peroxisomes possess more than fifty enzymes and fulfill a multitude of biological tasks. They actively participate in apoptosis, innate immunity, and inflammation. In recent years, a considerable amount of evidence has been collected to support the involvement of peroxisomes in the pathogenesis of kidney injury. Recent Advances: The nature of the two most important peroxisomal tasks, betaoxidation of fatty acids and hydrogen peroxide turnover, functionally relates peroxisomes to mitochondria. Further support for their communication and cooperation is furnished by the evidence that both organelles share the components of their division machinery. Until recently, the majority of studies on the molecular mechanisms of kidney injury focused primarily on mitochondria and neglected peroxisomes. Critical Issues: The aim of this concise review is to introduce the reader to the field of peroxisome biology and to provide an overview of the evidence about the contribution of peroxisomes to the development and progression of kidney injury. The topics of renal ischemia-reperfusion injury, endotoxin-induced kidney injury, diabetic nephropathy, and tubulointerstitial fibrosis, as well as the potential therapeutic implications of peroxisome activation, are addressed in this review. Future Directions: Despite recent progress, further studies are needed to elucidate the molecular mechanisms induced by dysfunctional peroxisomes and the role of the dysregulated mitochondria-peroxisome axis in the pathogenesis of renal injury. Antioxid. Redox Signal. 25, 217-231.
\end{abstract}

\section{Introduction}

$\mathbf{I}^{\mathrm{N}}$ N 1954, IN EARLY electron microscopy studies of murine proximal tubular cells, Swedish doctoral student Johannes Rhodin described for the first time small spherical organelles and named them microbodies (85). These organelles were later biochemically characterized by De Duve and because of the high content of hydrogen peroxide $\left(\mathrm{H}_{2} \mathrm{O}_{2}\right)$-metabolizing enzymes, the structural term, microbodies, was replaced by a more functional term, peroxisomes (17).

Peroxisomes originally designated as fossil organelles have attracted growing attention and are nowadays recognized as essential players under physiological conditions and in disease.

Mammalian peroxisomes are $0.1-0.5-\mu \mathrm{m}$-sized singlemembrane organelles present in the majority of eukaryotic cells with the highest abundance in the liver and the kidney. The evolutionary origin of peroxisomes is still a matter of discussion (30). One of the recent theories postulates that the evolution of peroxisomes was a consequence of raising oxygen concentration in the archaic atmosphere (16). In contrast to mitochondria, peroxisomes are not remnants of endosymbiotic organisms, but rather have developed from an endomembrane compartment, most likely from specialized parts of the endoplasmic reticulum (91).

Similar to the evolutionary concept, the origin of peroxisomes (biogenesis) at the subcellular level is not completely resolved. The classical view of peroxisome biogenesis emphasizes the formation of new organelles from pre-existing peroxisomes through growth and division (57). However, several recent studies have demonstrated that peroxisomes can also arise de novo in a maturation process employing preperoxisomal vesicles budding from the endoplasmic reticulum (75).

Peroxisomes have a protein-rich fluid matrix that contains numerous enzymes. Peroxisomes possess specific proteins called peroxins that are encoded by corresponding PEX genes (82). More than 30 different peroxins have been described so

Department of Nephrology and Rheumatology, University Medical Center Göttingen, Göttingen, Germany. 
far. These proteins regulate peroxisomal proliferation, division, movement, import, and participate in degradation of aged or damaged organelles. Peroxisomes do not have DNA and must import proteins from the cytoplasm. Newly synthesized proteins are transported to peroxisomes by specific transport peroxins. These cytosolic protein transporters recognize a distinct amino acid sequence present on proteins predestined for peroxisomes, the so-called peroxisomal targeting signal (PTS) (11). Peroxisomal targeting signal 1 (PTS1) is a carboxy-terminal serine-lysine-leucine (SKL) tripeptide sequence recognized by PEX5 and represents the main PTS for peroxisomal matrix proteins. Peroxisomal targeting signal 2 (PTS2) is an amino-terminal 11 amino acid sequence present on a small number of peroxisomal matrix proteins. Peroxisomal membrane proteins are tagged by a membrane-targeting signal (mPTS) that has not been explored in such detail as PTS for the matrix proteins.

The exact steps of recognition, binding, and import of peroxisomal proteins from cytosol to peroxisomes are far too complex to describe in its entirety here. For more information, please refer to an excellent review by Rucktäschel et al. (88). This review will briefly describe the relevant molecular mechanisms involved in protein import into peroxisomes.
The import of peroxisomal matrix proteins can be divided into four consecutive steps (49). (i) The cytosolic receptors (peroxins) recognize peroxisomal matrix proteins located after synthesis in the cytoplasm via PTS. Peroxin 5 (PEX5) recognizes and binds PTS1-containing proteins and peroxin 7 (PEX7) PTS2-containing proteins in the cytosol. The protein-receptor complexes are transported to the peroxisomal membrane (ii) where they dock to peroxin 14 (PEX14). Then, the protein-receptor complex is integrated into (iii) and subsequently translocated across the peroxisomal membrane. (iv) After the cargo release within the peroxisomal matrix, PEX5 or PEX7 is detached and exported back to cytosol (Fig. 1) (78). The exact mechanisms of protein translocation across the peroxisomal membrane are not clear. One of the current theories assumes the formation of a transient membrane pore through the interaction of PTS receptor PEX5 with the docking peroxin PEX14 (68).

Peroxisomal membrane proteins are recognized and bound by cytosolic peroxin 19 (PEX19) via a specific mPTS. PEX19 interacts with peroxisomal membrane-anchored PEX3, which is followed by release and incorporation of the transported proteins into the membrane. Then, PEX19 is exported back to the cytoplasm (87) (Fig. 1). A small group of membrane

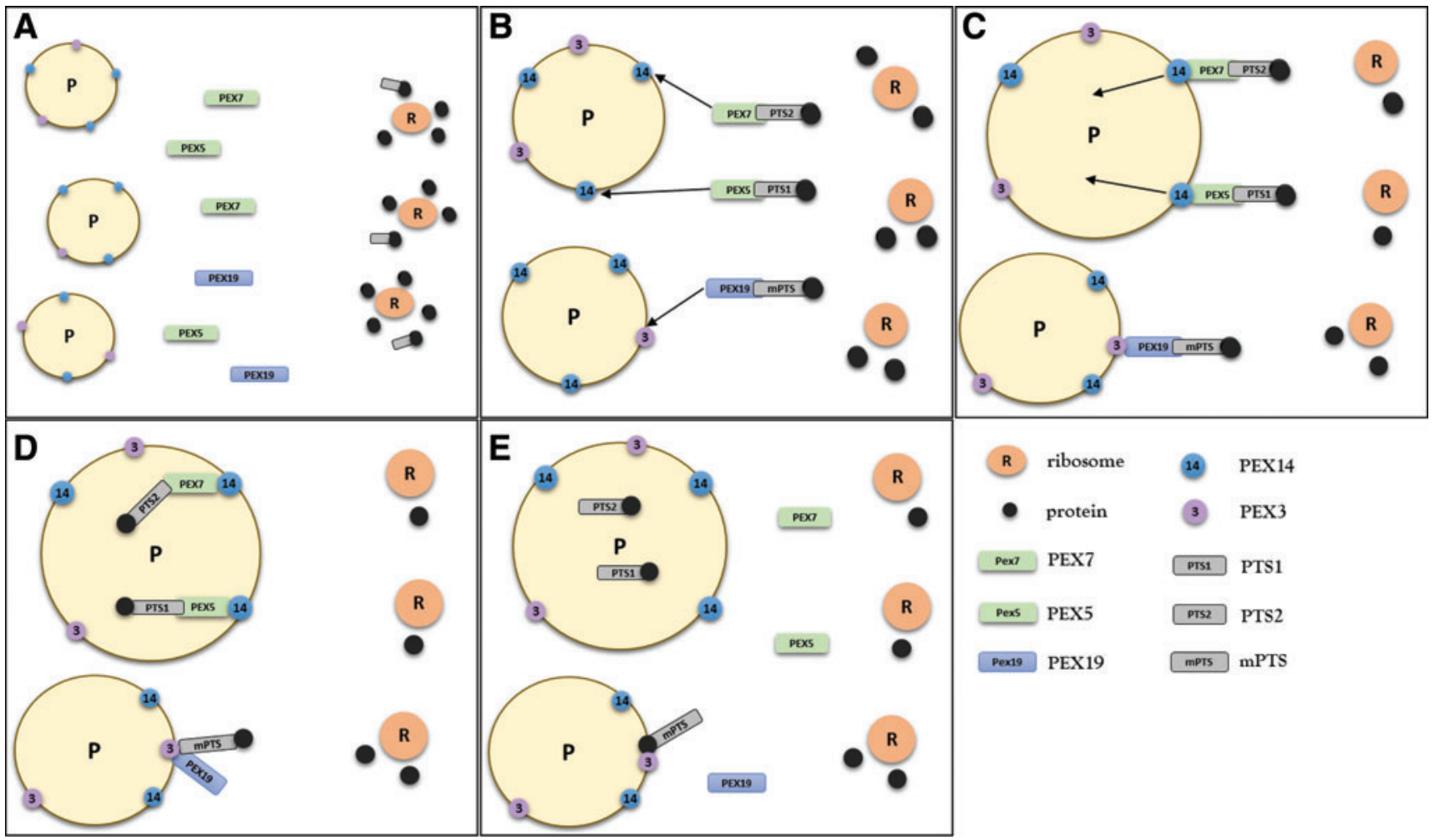

FIG. 1. Import of peroxisomal proteins. (A, B) Peroxisomal matrix proteins synthesized on cytoplasmic ribosomes (R) possess one of two distinct amino acid sequences called peroxisomal targeting signal (PTS) 1 and PTS2. Peroxisomal targeting signals are recognized and bound by specific cytosolic receptors, PTS1 by peroxin (PEX) 5 and PTS2 by PEX7. (C) The protein-receptor complexes are transported to peroxisomes (P) where they interact with PEX14 and dock to the peroxisomal membrane. (D) Next, the protein-receptor complexes are translocated across the membrane and the proteins are released into the peroxisome matrix. (E) After the release of cargo proteins, PEX5 and PEX7 shuttle back to the cytosol. Peroxisomal membrane proteins have a membrane peroxisomal targeting signal (mPTS) that is recognized by PEX19. PEX19 transports the membrane proteins to peroxisomes where they dock to PEX3. Subsequently, the proteins are integrated into the peroxisome membrane and PEX19 is released back to the cytosol. To see this illustration in color, the reader is referred to the web version of this article at www.liebertpub.com/ars 
proteins lacks the mPTS sequence recognized by PEX19. These proteins are transported to peroxisomes by a vesiclemediated mechanism via the endoplasmic reticulum (67).

Peroxisomes are surprisingly versatile organelles that accomplish a multitude of biological tasks. Their comprehensive metabolic apparatus encompasses more than 50 enzymes. The numerous metabolic tasks require reliable substrate and cofactor transport systems, in particular for the two most important peroxisomal tasks, the $\beta$-oxidation of fatty acids (FAO) and $\mathrm{H}_{2} \mathrm{O}_{2}$ metabolism (77).

The peroxisomal membrane is permeable to small metabolites up to $500 \mathrm{Da}$ in size. The internalization of larger molecules, such as fatty acids, adenosine triphosphate (ATP), or coenzyme A, requires specific receptors. Several membraneincorporated ATP-binding cassette (ABC) transporters facilitate the import of fatty acids processed by peroxisomal FAO (104). Three ABC transporters belonging to subfamily D have been identified in mammalian peroxisomes (73). ABCD3, also known as peroxisomal membrane protein 70 (PMP70), is experimentally used as a structural marker of peroxisomes (86).

Contribution of peroxisomes to the pathogenesis of human diseases has been widely accepted since the discovery of disorders caused by defective peroxisomal biogenesis and/or dysfunction of specific peroxisomal enzymes. Accumulating evidence indicates that peroxisomes are actively involved in apoptosis and inflammation (112), innate immunity (21), aging, and in the pathogenesis of age-related diseases, such as diabetes mellitus and cancer (27).

\section{Peroxisomal Fatty Acid Oxidation}

Renal cortex and particularly proximal tubules are heavily dependent on FAO as the major source of energy for numerous transport systems localized in this part of the nephron (58). FAO is exclusive to peroxisomes in prokaryotic organisms. In eukaryotes and particularly in mammals, peroxisomes cooperate closely with mitochondria and form a strategic partnership in cell energy metabolism (6). Mitochondria preferentially oxidize short and medium-chain fatty acids, whereas peroxisomes metabolize very long-chain fatty acids (VLCFA) with more than 22 carbons (69). Peroxisomal enzymes shorten the long chain of VLCFA, which are subsequently transported to mitochondria and oxidized to acetyl-CoA (83). Since peroxisomes do not contain respiratory chain enzymes, peroxisomal FAO is not directly coupled to generation of ATP (indirectly through anaplerotic reactions for mitochondria) and most of the energy is released as heat. Peroxisomal FAO is unique due to the generation of $\mathrm{H}_{2} \mathrm{O}_{2}$, a by-product of the oxidative reactions. Despite the functional interconnection between peroxisomes and mitochondria, FAO enzymes differ between these two organelles. The first step in peroxisomal FAO is catalyzed by acyl-CoA oxidase $(\mathrm{ACOX})$, followed by reactions catalyzed by bifunctional enzyme and 3-ketoacyl-CoA thiolase $(37,43)$. Dysfunction of peroxisomal enzymes, in particular of the rate-limiting ACOX, results in accumulation of unmetabolized fatty acids with potentially harmful consequences for the cell. Peroxisomes can perform different metabolic functions, depending on cell type and environment. A short overview of peroxisomal metabolic tasks is presented in Table 1 [adapted from Smith and Aitchison (94)]. In addition to FAO, peroxisomes can $\alpha$ - and $\beta$-oxidize a wide range of
Table 1. Important Peroxisomal Metabolic Tasks in Mammalian Cells

\begin{tabular}{ll}
\hline Biosynthesis & \multicolumn{1}{c}{ Degradation } \\
\hline Signaling molecules & Prostaglandins \\
Polyunsaturated fatty acids & Very long-chain fatty acids \\
Bile acids & Amino acids \\
Plasmalogens & Hydrogen peroxide \\
Purines & Superoxide radical \\
& Purines \\
\hline
\end{tabular}

natural and xenobiotic compounds containing the fatty acyl chain. Peroxisomes play a crucial role in the biosynthesis of ether phospholipids (plasmalogens) that are abundant in the nervous system. Peroxisomal participation in the metabolism of arachidonic acid advocates in favor of their role in cell signaling and apoptotic pathways (70).

Peroxisome proliferator-activated receptor alpha (PPAR $\alpha)$ is the principal regulator of activation and proliferation of peroxisomes. PPAR $\alpha$ is stimulated by hypolipidemic drugs (fibrates) and by naturally occurring ligands of the arachidonic cascade, such as leukotrienes. Upon activation, PPAR $\alpha$ translocates into the nucleus and binds to a specific DNA sequence called peroxisome proliferator-activated receptor (PPAR) response element located in the promoter region of genes encoding peroxisomal (and mitochondrial) FAO enzymes (92). PPAR $\alpha$ knockout mice have a normal number of peroxisomes, but an abolished proliferation after stimulation with PPAR $\alpha$ ligands (59). In recent years, several PPAR $\alpha$ independent activators of peroxisomes, such as PPARgamma coactivator (PGC-1 $\alpha$ ) or sirtuin 1 (SIRT1), have been reported in the literature $(3,34)$.

\section{Peroxisomal Metabolism of Reactive Oxygen Species}

Peroxisomal oxidases generate excessive amount of $\mathrm{H}_{2} \mathrm{O}_{2}$ and require reliable scavenger mechanisms. This is exemplified by the highest cellular concentration of catalase in peroxisomes. The dual function of peroxisomes in metabolism of $\mathrm{H}_{2} \mathrm{O}_{2}$ predestines them for a decisive role in the precisely regulated redox homeostasis. Dysfunction of peroxisomal antioxidant enzymes may result in $\mathrm{H}_{2} \mathrm{O}_{2}$ leakage into the cytoplasm with harmful consequences for the cell. There is increasing evidence on the close connection between peroxisomal, mitochondrial, and cellular redox homeostasis. The inactivation of peroxisomal catalase causes alterations of mitochondrial membrane potential and stimulates generation of mitochondrial reactive oxygen species (ROS) (51). Koepke et al. demonstrated progeric effects of catalase dysfunction (56). Cellular aging is associated with peroxisome senescence and decreased import of catalase. This study also demonstrated that restoration of peroxisomal catalase in aging cells improves the overall redox balance and reduces cellular senescence.

It is important to mention that low (hormetic) concentrations of ROS function as mediators of cell signaling. Low hormetic levels of $\mathrm{H}_{2} \mathrm{O}_{2}$ stimulate antiaging pathways (e.g., activation of autophagy responsible for cell surveillance and removal of aged organelles). High concentrations of $\mathrm{H}_{2} \mathrm{O}_{2}$ exacerbate organellar and cellular aging (90). Recalling the close link between peroxisomal and mitochondrial metabolism, 
it becomes evident that the peroxisome-mitochondria partnership must have a major role in cellular metabolism and functions. The previously held rigid view of mitochondria as the exclusive generator of ROS has been challenged by new findings coming from studies on peroxisomes. Further support for their communication and cooperation is furnished by the evidence that both organelles share the components of their division machinery (92). Taken together, peroxisomal disturbances may result in significant, and under certain circumstances, fatal consequences for individual cells, organs, or even the whole organism, as demonstrated in primary peroxisomal disorders.

\section{Peroxisomal Disorders and Their Animal Models}

Hereditary peroxisomal disorders cause devastating human diseases. In general, inborn peroxisomal defects can be categorized in (i) peroxisomal biogenesis disorders and (ii) peroxisomal disorders caused by defects of peroxisomal enzymes or transporters. The common metabolic feature observed in peroxisomal diseases is the accumulation of VLCFA normally oxidized in peroxisomes. (i) Zellweger syndrome (cerebrohepatorenal syndrome) is the prototypical peroxisomal biogenesis disease caused by mutations in PEX genes encoding specific peroxins. Depending on the mutation, peroxisomes may be completely absent or present as empty ghost peroxisomes with severely impaired import functions. (ii) Single enzyme deficiencies or transporter defects cause peroxisomal disorders characterized by accumulation of specific metabolic substrate (e.g., phytanic acid in Refsum disease). Patients with peroxisomal enzyme or transporter disorders have structurally intact, but functionally impaired, organelles. A recent review by Braverman provides more detailed and updated information on primary peroxisomal disorders (9).

There is increasing evidence that minor and/or temporary perturbations of peroxisomal functions may be involved in the pathogenesis of common human diseases. Peroxisomal dysfunction has been reported in the molecular pathogenesis of Parkinson's and Alzheimer's diseases (48, 108). Peroxisomes play an important role in human aging and in the pathogenesis of age-related diseases (27). The emerging evidence that human immunodeficiency virus and influenza virus are exploiting peroxisomes for replicative purposes may provide novel targets for therapeutic intervention against viral infections (76).

The majority of the data on peroxisomes originated in studies of peroxisomal mutants generated in different yeasts. There is no naturally occurring animal model of a peroxisomal disorder. Baes created the first experimental mouse model for PEX5 in 1997 (2). At present, animal models with deficiency of PEX5, PEX7, PEX11, and PEX13 are available. The common problems observed in these animals are severe neurodevelopmental disturbances caused by widespread tissue accumulation of VLCFA. The high perinatal and postnatal mortality in peroxin knockout models precludes their use for investigating the pathogenesis of temporary and minor alterations of peroxisomal functions. The implementation of conditional knockouts with elimination of peroxisomes in specific tissues and at a specific developmental stage may overcome these hurdles in the future (100). The lack of natural models for specific peroxisomal defects also implicates rather subtle and/or temporary alterations of peroxisomes in the pathogenesis of common disorders.

\section{Peroxisomal Homeostasis and Autophagy}

Cells regulate the number of organelles through continual interplay between biogenesis and degradation. This constant turnover is essential for preservation of cellular and organellar competence. Experimental studies demonstrated that peroxisomes have a half-life of circa $48 \mathrm{~h}$ under basal conditions and are primarily degraded by autophagy (44). Autophagy is a highly conserved lysosome-dependent pathway that maintains the quality of cellular components through continual removal of redundant or damaged proteins or entire organelles (72). The molecular basis of autophagy-mediated degradation of peroxisomes called pexophagy has been extensively studied in yeast and reviewed in (97). Contrary to yeast, the molecular details of mammalian pexophagy are not completely understood.

There are three independent systems for clearance of peroxisomes: (i) Lon protease, (ii) 15-lipooxygenase-mediated lysis, and (iii) pexophagy (autophagy of peroxisomes) (110). Lon protease is an ATP-dependent enzyme that catalyzes proteolytic digestion of peroxisomal proteins and accounts for removal of about $20 \%$ of peroxisomes. Activation of 15lipooxygenase leads to disruption of the peroxisomal membrane; however, this mechanism eliminates only a small fraction of peroxisomes (111). The most important pathway for removal of peroxisomes is autophagy. Activation of autophagy in yeast is primarily a metabolic adaptation to changed environment to maintain nutritive balance under starvation. In mammalian cells, autophagy regulates and maintains homeostasis by eliminating aged, damaged, and dysfunctional cellular constituents. Three main types of autophagy have been described: macroautophagy, microautophagy, and chaperone-mediated autophagy (98).

The dominant form of organellar autophagy in mammalian cells is macroautophagy. Macroautophagy begins with formation of a double-membrane structure around a cytoplasmic component called autophagosome. The autophagosome with engulfed proteins or organelles moves through the cytoplasm and fuses with the lysosome. The selective autophagy of peroxisomes requires the presence of specific cargo receptors (97). Among them, p62/SQSTM1 has been directly associated with mammalian pexophagy. Autophagy recognizes monoubiquitinated proteins, and monoubiquitination of peroxisomal proteins leads to activation of pexophagy (55). P62/ SQSTM1 possesses an ubiquitin-binding domain (UBD) and an LC3-interacting region (LIR) (4). During autophagy, the cytosolic form of LC3 (LC3-I, microtubule-associated protein light chain 3) is conjugated with phosphatidylethanolamine (PE) to generate LC3-II, which is recruited to the autophagosomal membrane (highly lipophilic PE promotes the integration of LC3-II into the lipid membrane). P62/ SQSTM1 binds ubiquitinated proteins of the peroxisomal membrane and LC3-II on the autophagosome via UBD and LIR, respectively, and docks peroxisomes to the autophagosome. The subsequent fusion of autophagosome with lysosome creates an autolysosome (autophagy lysosome), where the final stage of digestion takes place (Fig. 2). Since p62/SQSTM1 is degraded by autophagy at the same time as its ubiquitinated cargo, this protein has been used as a marker of the autophagy/pexophagy flux. In other words, the 


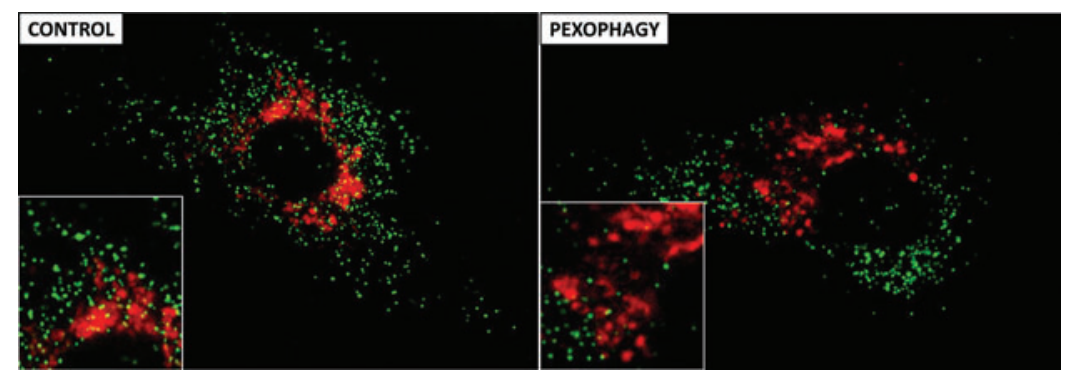

FIG. 2. Pexophagy (lysosomal autophagy of peroxisomes) in human endothelial cells treated with endotoxin. Representative immunofluorescence images show PTS1-GFP-labeled peroxisomes (green) and LysoTracker Red-stained lysosomes (red). Pexophagy was induced by treatment with a sublethal dose of endotoxin (PEXOPHAGY). Untreated cells served as controls (CONTROL). The image of the cells treated with endotoxin demonstrates an obvious reduction of peroxisome numbers in the vicinity of lysosomes (PEXOPHAGY). Insets show zoomed views for better presentation. Adapted from Vasko et al. (102). To see this illustration in color, the reader is referred to the web version of this article at www.liebertpub.com/ars

inhibition of autophagy leads to accumulation of p62/ SQSTM1 and vice versa. The accumulation of peroxisomes in p62/SQSTM1 knockout models supports the role of p62/ SQSTM1 in pexophagy. The preserved motility of peroxisomes is an important prerequisite for accurate functioning of pexophagy. PEX14 has been shown to interact with tubulin, which may affect the motility of peroxisomes. This assumption is corroborated by experimental findings demonstrating that PEX14-deficient peroxisomes lose their ability to move along microtubules (5).

\section{Peroxisomes and Kidney}

Peroxisomes are most abundant in the liver and the kidney where they were originally described by Rhodin (85). They are particularly dense in proximal tubules with negligible presence in glomeruli, distal tubules, and collecting ducts $(64,65)$. Immunohistochemical studies demonstrated the presence of peroxisomal FAO enzymes (ACOX, bifunctional protein, and 3-ketoacyl-CoA thiolase) and catalase in tissue samples from human renal biopsies (64).

Most of the previous studies focused on mitochondria and by and large neglected peroxisomes. Studies examining the contribution of peroxisomes to the pathogenesis of renal disorders are quite scarce.

All parts of the nephron are able to utilize fatty acids as a source of energy. Mitochondrial FAO is equally distributed in the proximal and the distal parts of the nephron. The proximal tubule is the site of numerous energy-consuming transport processes. Proximal tubules exhibit a low rate of glycolysis and critically depend on a functional FAO. Therefore, in addition to mitochondrial FAO, proximal tubular cells possess peroxisomal FAO with a capacity comparable with that of the liver cells (58). The distribution of ACOX, the key peroxisomal FAO enzyme is restricted to the proximal tubule. Disturbances in mitochondrial and/or peroxisomal FAO lead to an increase of unmetabolized fatty acids (backward failure) and simultaneously to decreased energy production (forward failure). High tissue levels of free fatty acids (FFAs) inhibit proximal tubule $\mathrm{Na}^{+} \mathrm{K}^{+}$-ATPase, destabilize mitochondrial membrane potential, and stimulate inflammatory response $(25,79)$.

Most of the pioneer data on peroxisomes in the pathogenesis of kidney injury originate from studies using ischemiareperfusion models of acute kidney injury (AKI). During tubular regeneration after AKI, mitochondria and endoplasmic reticulum appear before peroxisomes. Peroxisomes regenerate later at the same time as lysosomes (8). In mercuric chlorideinduced acute tubular necrosis, peroxisomes appear on the fourth day of regeneration and their number reaches the normal distribution in the fourth week (8).

\section{Ischemic AKI}

Proximal tubular cells are the major targets of ischemic injury during acute renal failure (63). Increased parenchymal levels of FFAs and decreased ATP levels are consistent findings in the ischemic kidney.

Mitochondria have long been considered to play a central role in cell dysfunction during ischemia-reperfusion and hypoxia-reoxygenation kidney injury (105). Ruidera et al. showed that renal ischemia impairs FAO in both organelles, mitochondria and peroxisomes. The study demonstrated a comparable loss of FAO activity for short-, long-, and very long-chain fatty acids and an equal degree of mitochondrial and peroxisomal FAO dysfunction (89). Sixty minutes of renal ischemia reduces the activity of FAO almost by 70 percent. Phospholipase A2 activated in the ischemic kidney degrades phospholipid-rich membranes and additionally increases the levels of unsaturated fatty acids elevated due to the dysfunctional FAO. Excessive parenchymal accumulation of FFAs stimulates their oxidation to lipid peroxides. Tissue levels of lipid peroxides in kidneys explanted from rats subjected to renal ischemia are about 2.5-fold higher than in control animals (89).

ROS are the main etiological agents in the pathophysiology of ischemia-reperfusion injury. Reperfusion of ischemic kidney leads to excessive generation of ROS and further aggravates the ischemic injury. Peroxisomal antioxidant mechanisms, including superoxide dismutase, glutathione peroxidase, and the key enzyme catalase, participate in the detoxification of peroxisomal (and cellular) ROS.

The harmful effects of ischemia-reperfusion injury on organelles other than peroxisomes, in particular on mitochondria, have been reported by many studies. Gulati et al. showed for the first time that renal ischemia-reperfusion is accompanied by functional and structural damage of peroxisomes (33). Almost $90 \%$ of cellular catalase activity is localized to peroxisomes. The loss of catalase activity during renal ischemia is largely caused by the inactivation of the enzyme. Ischemia-induced generation of $\mathrm{H}_{2} \mathrm{O}_{2}$, together with 
intracellular acidosis, predisposes catalase to form an enzymatically inactive complex. In contrast to ischemia, proteolysis and decreased synthesis of catalase protein are responsible for the suppression of catalase activity during reperfusion. The rate of peroxisomal FAO assessed by the oxidation of lignoceric acid (24 carbon VLCFA metabolized almost exclusively by peroxisomes) decreases with the duration of renal ischemia (53\% of control after $60 \mathrm{~min}$ and $43 \%$ of control after $90 \mathrm{~min}$ of ischemia). During reperfusion following ischemia, the kidney is able to restore FAO and catalase activity unless the duration of the preceding ischemia exceeds $60 \mathrm{~min}$. After a longer period of ischemia, subsequent reperfusion causes structural alterations of peroxisomes with cytosolic release of their enzymes and finally a global deterioration of the organelle (33).

Peroxisomal FAO includes several steps catalyzed by different enzymes. The initial and rate-limiting step is catalyzed by ACOX, whereby fatty acyl-CoA is reduced to trans2-enoyl-CoA accompanied by consumption of oxygen and generation of $\mathrm{H}_{2} \mathrm{O}_{2}$. A multifunctional protein possessing the activities of enoyl-CoA hydratase and 3-hydroxyacyl-CoA dehydrogenase catalyzes the following two reactions. In the final step, 3-ketoacyl-CoA is cleaved by 3-ketoacyl-CoA thiolase into acetyl-CoA and a saturated acyl-CoA having two carbons less than the original molecules, whereas peroxisomal FAO seems to be mostly inducible; mitochondrial FAO has a rather constitutive nature. Peroxisomal FAO enzyme activities are regulated mainly by the rate of their protein synthesis (36).

Peroxisomal FAO, the main source of cellular $\mathrm{H}_{2} \mathrm{O}_{2}$, is sensitive to excess $\mathrm{H}_{2} \mathrm{O}_{2}$. The exposure of peroxisomes, isolated from a healthy rat kidney, to high $\mathrm{H}_{2} \mathrm{O}_{2}$ results in inhibition of lignoceric acid oxidation. Similarly, the inhibition of catalase activity by aminotriazole (catalase inhibitor) reduces the oxidation of lignoceric acid in peroxisomes to about 55\% of control (32). Among peroxisomal FAO enzymes, the rate-limiting ACOX is more sensitive to ischemic stress and largely contributes to the loss of FAO capacity in ischemia-reperfusion kidney injury.

Renal ischemia decreases FAO and catalase activity. The reperfusion phase following ischemia generates significant oxidative stress. The accumulation of unmetabolized fatty acids augmented by inactivated and/or degraded catalase promotes lipid peroxidation and cellular damage. Interestingly, renal ischemia-reperfusion injury exhibits negative effects also on distant organs. Fifty minutes of renal ischemia and subsequent reperfusion induce oxidative cardiac injury characterized by increased myocardial levels of lipid peroxides and decreased activities of myocardial antioxidant enzymes (46).

\section{Septic AKI}

Sepsis is the most common cause of AKI in critically ill patients. Magnetic resonance imaging shows alterations in renal parenchyma already $6 \mathrm{~h}$ after septic insult and underlines the importance of early subclinical alterations in septic kidney $(18,23)$.

Endotoxin-mediated injury is a very good model of cellular stress that extensively stimulates metabolic and oxidative pathways, two processes related to peroxisomes. The proximal tubule can be divided into three segments that differ anatomically and functionally. The S1 segment corresponds to the initial two-thirds of the pars convoluta, the S2 segment extends to the initial part of the pars recta, and the S3 segment includes the rest of the pars recta to its termination in the outer medulla (13). Systemically administered endotoxin is freely filtered through the glomerulus and almost exclusively reabsorbed in the S1 segment through Toll-like receptor 4dependent endocytosis. The interaction with endotoxin activates the $S 1$ segment to secrete inflammatory cytokines such as tumor necrosis factor-alpha (TNF- $\alpha)$ (52). In contrast to severe oxidative injury in the adjacent $\mathrm{S} 2$ and $\mathrm{S} 3$ segments, the S1 segment exhibits practically no oxidative stress, despite the heavy uptake of endotoxin. The S1 segment possesses several defense mechanisms, among them antioxidant/ cytoprotective enzymes, heme oxygenase-1 and SIRT1 (34, 52). Interestingly, whereas $\mathrm{S} 2$ and $\mathrm{S} 3$ segments have the highest density of peroxisomes, the $\mathrm{S} 1$ segment lacks these organelles. Moreover, S2 and S3 segments (but not S1) express TNF- $\alpha$ receptor- 1 that makes this part of the nephron more susceptible to TNF- $\alpha$-mediated injury. Both, S2 and S3 segments exhibit severe oxidative peroxisome damage already $4 \mathrm{~h}$ after administration of endotoxin, even before the mitochondrial injury occurs (24).

Our group demonstrated that systemic injection of a sublethal dose of endotoxin induces a biphasic response starting with a transient decrease followed by an increase of peroxisome numbers in the kidney of normal mice (102). Experimental studies revealed that peroxisomes have a half-life of $48 \mathrm{~h}$ and are mainly degraded by autophagy under basal conditions (44). The initial reduction of peroxisomes after the application of endotoxin results from increased degradation by activated pexophagy. Endotoxin-induced pexophagy eliminates damaged and dysfunctional organelles and helps to rejuvenate the kidney peroxisomal pool (Fig. 3). The activated pexophagy eliminates a substantial number of peroxisomes already $3 \mathrm{~h}$ after exposure to endotoxin. Pexophagy removes peroxisomes in toto and consequently reduces both generation and decomposition of $\mathrm{H}_{2} \mathrm{O}_{2}$ by $\mathrm{FAO}$ and catalase, respectively. Pexophagy preserves in this way the peroxisomal redox homeostasis (Fig. 4). Defective peroxisome removal/ recycling due to dysfunctional pexophagy consequently alters cellular redox homeostasis even under normal conditions. Cells with dysfunctional peroxisomes exhibit increased levels of oxidative stress and show a protracted elevation of $\mathrm{H}_{2} \mathrm{O}_{2}$ levels after exposure to endotoxin. Interestingly, mice with impaired pexophagy accumulate dysfunctional peroxisomes with active FAO and inactivated catalase. The animals suffer from chronically increased oxidative stress and show an exaggerated oxidative stress response to endotoxin.

Dysfunctional pexophagy impairs regeneration of peroxisomes and induces intraorganellar redox imbalance (Fig. 5). Peroxisomes import fatty acids via specific $\mathrm{ABC}$ transporters $(\mathrm{ABCD})$ residing in the peroxisomal membrane. ABCD3/ PMP70 functions as a transporter for long-chain fatty acids that are preferentially oxidized in peroxisomes (47). PEX14 is a small membrane-attached peroxin with an important role in catalase import into peroxisomes (Fig. 6). Endotoxin decreases the expression of PEX14 more than of ABCD3/ PMP70 and impairs the import of catalase more substantially compared with fatty acids. Peroxisomes exposed to endotoxin upregulate nitric oxide synthase and produce increased amounts of nitric oxide (95). Nitric oxide interacts with heme 


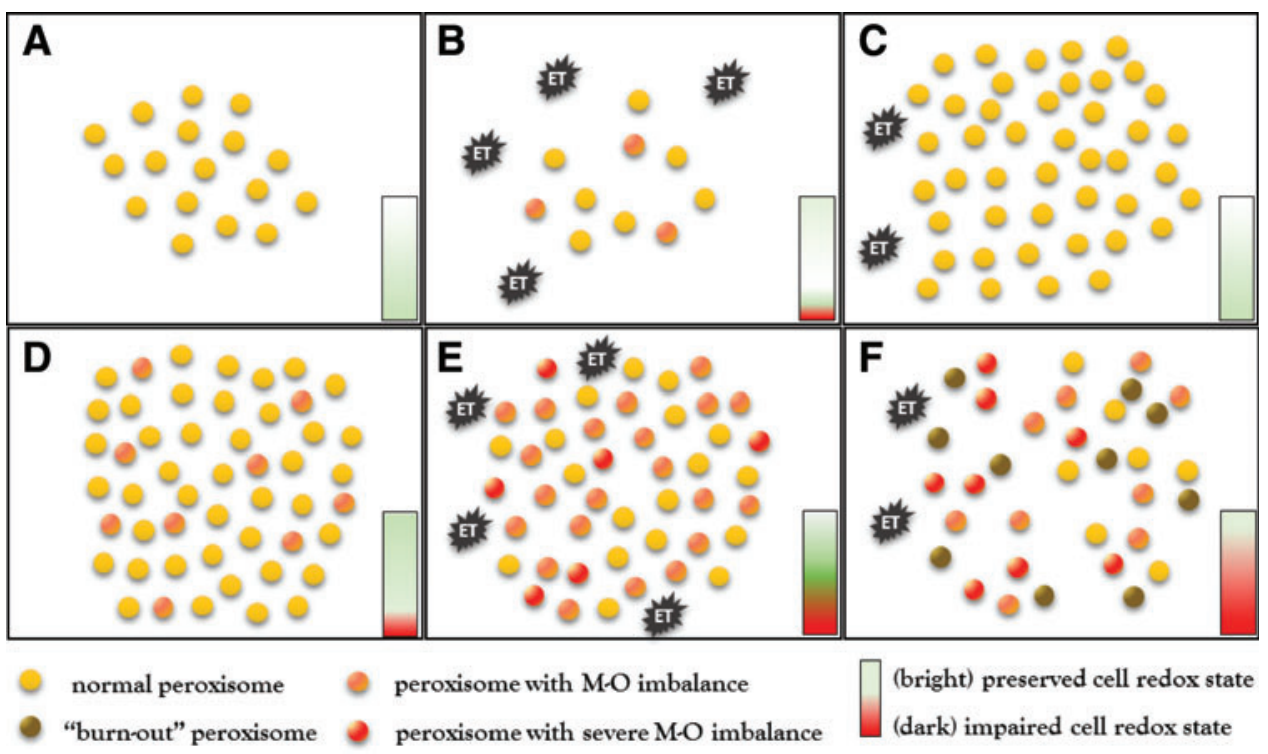

FIG. 3. Peroxisome turnover in (A-C) normal cells and in (D-F) cells with impaired pexophagy after stimulation with endotoxin (ET). (A-C) In normal cells, endotoxin causes slight impairment of the peroxisomal redox state. The simultaneous activation of pexophagy eliminates compromised organelles and helps to preserve the cellular redox balance. The second phase is characterized by proliferation of peroxisomes, which leads to quantitative and qualitative restoration of a functional peroxisomal pool. (D-F) Impaired pexophagy results in accumulation of dysfunctional peroxisomes with increased intraorganellar oxidative stress. Endotoxin further exacerbates peroxisomal redox imbalance and worsens intraorganellar homeostasis. Compromised maintenance mechanisms due to impaired pexophagy perpetuate oxidative stress and result in gradual deterioration of peroxisomal (peroxisome burnout) and later cellular homeostasis. To see this illustration in color, the reader is referred to the web version of this article at www.liebertpub.com/ars

groups of catalase and inactivates the enzyme without affecting the protein levels (93). The activity of peroxisomal ACOX during endotoxic stress is initially increased in cells with impaired pexophagy, perhaps as a consequence of an aberrant activation of PPAR $\alpha$. This produces a functional uncoupling between active ACOX and inactive catalase. The accumulation of oxidative stress further perturbs peroxisomal redox state and gradually decreases the initially preserved FAO (ACOX). This may result in global deterioration of peroxisomal homeostasis-peroxisome burnout. Hence, endotoxin-activated pexophagy not only rejuvenates the peroxisomal pool but also prevents the development of

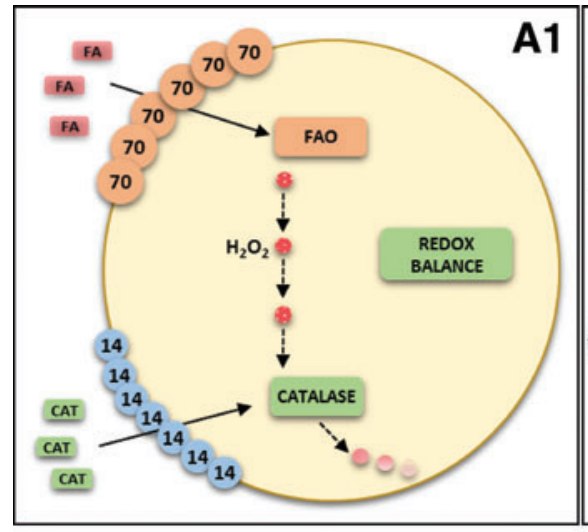

70 ABCD3/PMP70

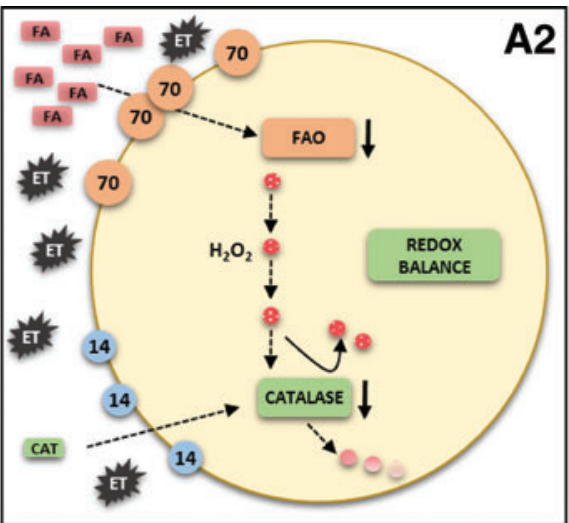

Endotoxin

Catalase

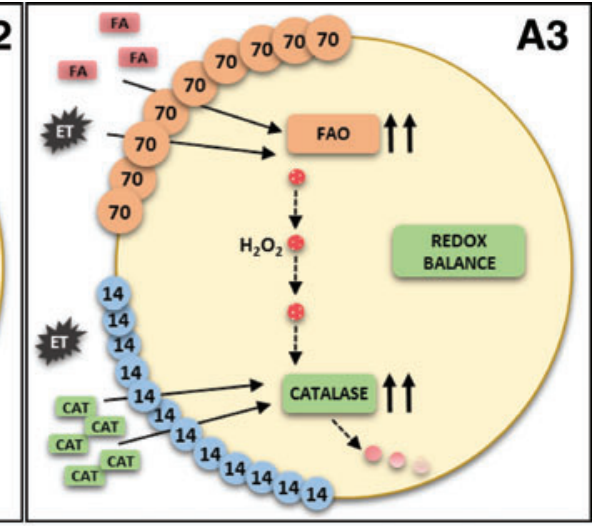

e $\mathrm{H}_{2} \mathrm{O}_{2}$

FIG. 4. Schematic presentation of peroxisomal metabolic-oxidative balance in normal cells after exposure to endotoxin (ET). (A1, A2) Endotoxin decreases the expression of fatty acid transporter ABCD3/PMP70 and reduces the activity of fatty acid oxidation (FAO) enzymes. Parallel decrease of PEX14 expression (more repressed compared with $\mathrm{ABCD}$ 3/PMP70) and reduced catalase activity cause minor impairment of peroxisomal redox homeostasis. Properly functioning pexophagy removes dysfunctional organelles (A3) and helps to restore peroxisomes with preserved metabolicoxidative balance. PMP70, peroxisomal membrane protein 70. To see this illustration in color, the reader is referred to the web version of this article at www.liebertpub.com/ars 

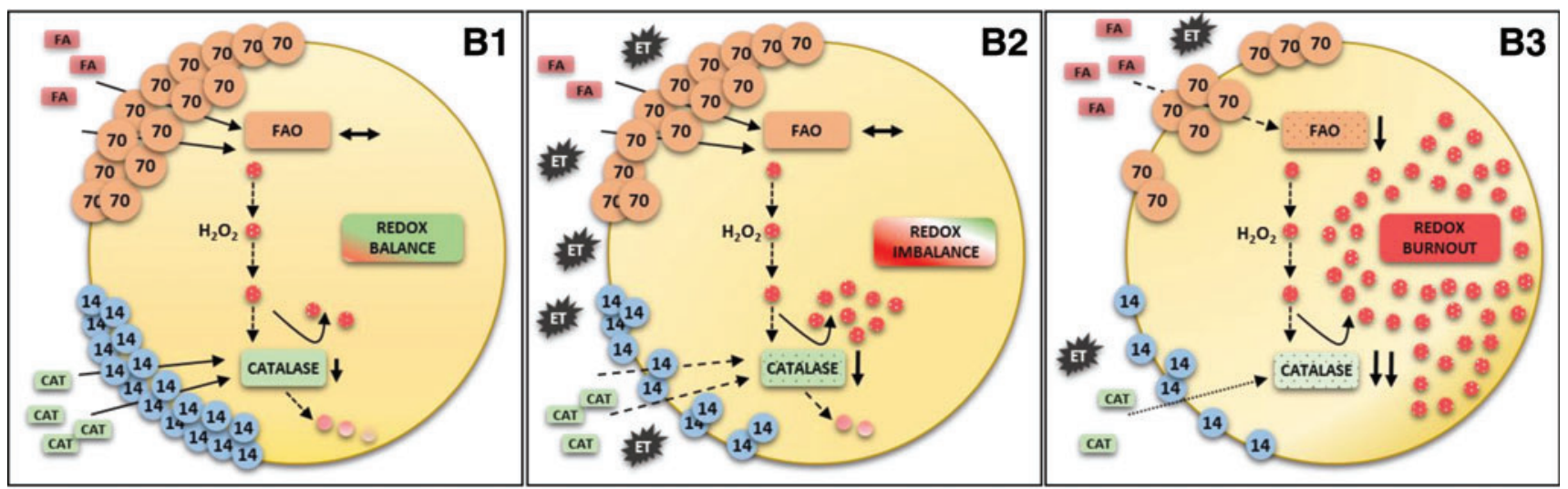

70

ABCD3/PMP70 14 PEX14

Endotoxin

Free fatty acids

Catalase

- $\mathrm{H}_{2} \mathrm{O}_{2}$

FIG. 5. Schematic presentation of peroxisomal metabolic-oxidative imbalance in cells with impaired pexophagy after exposure to endotoxin (ET). (B1) Pexophagy impairment results in accumulation of dysfunctional peroxisomes with relatively preserved FAO and at the same time significantly decreased activity of catalase, which results in increased levels of oxidative stress under normal conditions. (B2) Endotoxin additionally worsens intraperoxisomal redox state and aggravates dysfunction of the organelle. Compromised pexophagy is not able to eliminate the injured organelles, which perpetuates metabolic-oxidative imbalance and (B3) finally ends up in global deterioration of peroxisomal homeostasisperoxisome burnout. To see this illustration in color, the reader is referred to the web version of this article at www.liebertpub.com/ars

intraperoxisomal redox imbalance. Endotoxic AKI is an extreme model of peroxisomal dysfunction. A chronic lowgrade imbalance between pro- and antioxidant peroxisomal pathways has been previously reported in hereditary peroxisomal disorders (26). The above data demonstrate that such metabolic-oxidative imbalance patterns can arise in endotoxin-stressed renal peroxisomes. There is emerging evidence that very low concentrations of circulating endotoxin released by bacterial flora of the digestive system are associated with increased cardiovascular burden in patients with chronic kidney disease (71). Szeto demonstrated a positive association between the levels of circulating endotoxin and the degree of renal impairment (96). Keeping in mind the interaction of endotoxin with peroxisomes, these organelles should be considered as potential culprits in the progression of chronic kidney disease.

Cecal ligation and puncture (CLP) is a model of severe polymicrobial sepsis that simulates human septic peritonitis (40). During activation of autophagy, cytosolic LC3-I is conjugated to PE to form LC3-II that aggregates on the autophagosomal membrane. Increased amounts of LC3 aggregates (autophagosomal membrane-bound) present in renal
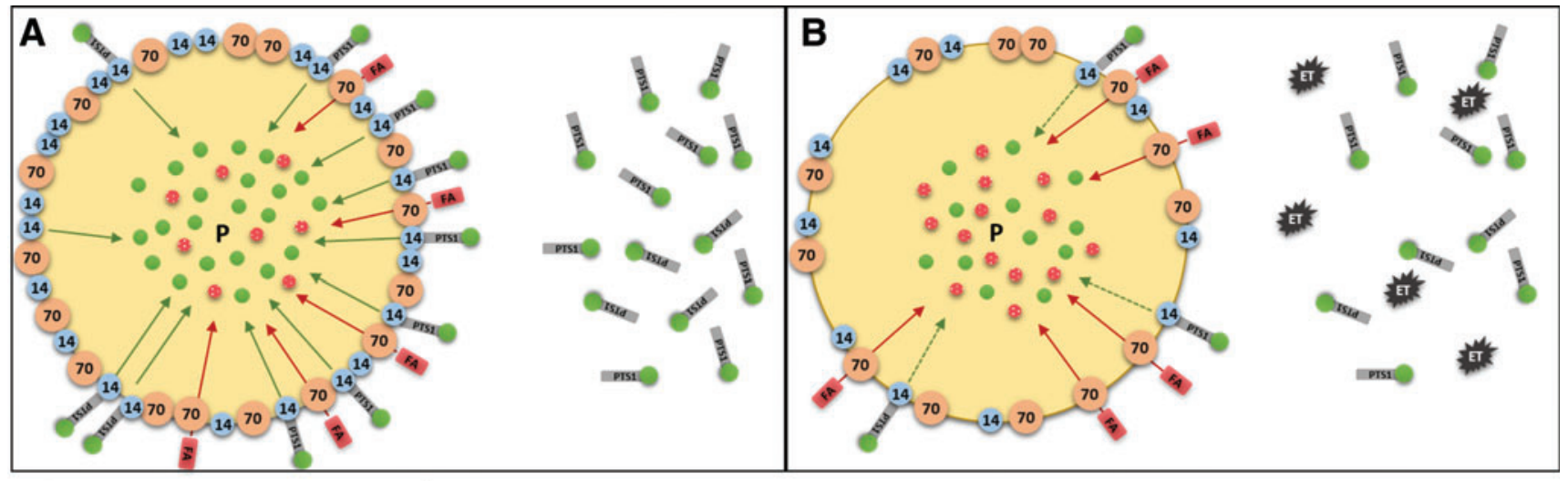

70 ABCD3/PMP70

14. PEX14

Endotoxin

FA Free fatty acids

Mrsi PTS1-catalase $\oplus \mathrm{H}_{2} \mathrm{O}_{2}$

FIG. 6. Endotoxin impairs protein import into peroxisomes. Peroxisomal matrix proteins are synthesized on cytoplasmic ribosomes and their final destination is tagged by PTS1. PTS1 is required for docking to membrane-associated PEX14 that assists with import of matrix proteins into peroxisomes. Endotoxin exhibits more profound effect on PEX14 (catalase import) than ABCD3/PMP70 (fatty acid import) expression, which contributes to peroxisome redox imbalance during endotoxic stress. To see this illustration in color, the reader is referred to the web version of this article at www.liebertpub.com/ars 
parenchyma $3 \mathrm{~h}$ after CLP indicate activation of autophagy. The predominant occurrence of the cytosolic LC3-I form suggests suppression of autophagy 9 and $18 \mathrm{~h}$ after CLP. At this later time point, the animals show increased serum creatinine levels and severe renal injury. Different from the sublethal model of endotoxic AKI, the decline of autophagy in severe polymicrobial sepsis appears to aggravate tubular injury (40). The initially upregulated and later downregulated autophagy/pexophagy (coordinated biphasic response) seem to be protective in endotoxic AKI. Hence, accurately dosed and precisely coordinated activation and deactivation of autophagy/pexophagy play a critical role in organellar and cellular homeostasis during septic renal injury.

Peroxisomal alterations reported in various models of AKI may represent mechanisms involved in more common kidney disorders, however, at a lower intensity and with long-term implications.

\section{Diabetic nephropathy}

Diabetic nephropathy (DN) is the leading cause of endstage renal disease in developed countries. Chronic hyperglycemia stimulates the production of ROS and angiotensin, which in turn accelerates the progression of tubulointerstitial fibrosis $(41,101)$. Experimental data indicate an important role for ROS in the nephropathy of diabetes. Hence, most of the studies analyzing peroxisomes in DN focused on the oxidative stress and the role of peroxisomal catalase.

Mammalian catalase is a highly conserved heme-containing tetrameric protein with a molecular mass of $240 \mathrm{kDa}(84)$. The overexpression of catalase reduces oxidative stress and mitigates oxidative injury in vascular smooth muscle cells and ischemic myocardium $(12,54)$. Transgenic diabetic mice overexpressing catalase in proximal tubules exhibit decreased levels of ROS, angiotensin, plasminogen activator inhibitor type 1 (PAI-1), and proapoptotic p53 (10).

Studies scrutinizing mechanisms induced by catalase deficiency are helpful in defining the potential contribution of peroxisomes to diabetic kidney disease. Diabetic catalase knockout (CKO) mice have higher serum creatinine and FFA levels. They develop higher level proteinuria compared with diabetic wild-type mice, despite the blood glucose levels being similar (45). CKO mice exhibit increased renal expression of profibrotic-transforming growth factor $\beta 1$ and decreased expression of antifibrotic bone morphogenetic protein 7. CKO mice and cultured catalase knockdown mesangial cells have impaired biogenesis of peroxisomes resulting from increased levels of $\mathrm{H}_{2} \mathrm{O}_{2}$. Mesangial cells typically increase peroxisomal biogenesis in response to physiological concentrations of $\mathrm{H}_{2} \mathrm{O}_{2}$ and this effect disappears when the $\mathrm{H}_{2} \mathrm{O}_{2}$ concentration exceeds a certain level (45). The nontoxic levels of $\mathrm{H}_{2} \mathrm{O}_{2}$ generated by FAO stimulate peroxisomal biogenesis to meet the metabolic demand of the cell. However, $\mathrm{H}_{2} \mathrm{O}_{2}$ concentrations above a certain level (modified by the balance between FAO and catalase) may cause peroxisomal injury. Catalase knockdown mesangial cells stimulated with low concentrations of $\mathrm{H}_{2} \mathrm{O}_{2}$ or phytanic acid (physiological substrate of peroxisomes) do not respond with activation of peroxisomal biogenesis and, even more, exhibit defective biogenesis of mitochondria (45) (Fig. 7). Moreover, the basal levels of mitochondrial ROS are significantly increased in catalase knockdown mesangial cells, supporting the idea of close interactions between mitochondrial and peroxisomal pathways. The above data provide evidence that endogenous catalase fulfills an important role in protecting the kidney from diabetic stress by maintaining peroxisomal and mitochondrial fitness.

In the streptozotocin-induced model of DN, a mismatch between increased FAO (ACOX) and decreased catalase activity results in metabolic-oxidative imbalance with overproduction of $\mathrm{H}_{2} \mathrm{O}_{2}$ and accelerated progression of the diabetic kidney disease (19).

Farnesyl transferase catalyzes farnesylation of small GTPase proteins such as Ras and Rho and plays therefore an important signaling role in the regulation of cell proliferation. Treatment of diabetic rats with farnesyl protein transferase inhibitor, FPTIII, has been shown to diminish diabetesinduced inhibition of catalase. This study indicates that inhibition of farnesyl transferase might prove beneficial in DN and that modulation of peroxisomal functions through Ras-/ Rho-GTPase signaling pathways may play a role (20).

\section{Renal cancer}

Resistance to chemotherapy and radiotherapy is a common feature of renal cancer. Because of defective mitochondrial oxidation, renal cancer cells obtain their energy primarily from glycolysis rather than oxidative phosphorylation (38). Interestingly, whereas proximal tubules of normal human kidney contain large numbers of peroxisomes, these organelles seem to be entirely absent in renal cancer cells. The absence of peroxisomes and mitochondrial disturbances in renal cancer cells result in alterations of fatty acid metabolism that may serve as potential targets for future therapeutic interventions $(28,29)$.

\section{PPAR alpha}

The results of numerous studies indicated that inhibited or dysfunctional FAO exhibits negative effects on renal injury. Functional FAO prevents accumulation of fatty acids, their peroxidation, and formation of lipid aldehydes that can further aggravate renal injury (66). For that reason, many of the follow-up studies focused on the potential protective effects of FAO stimulation in AKI.

PPARs belong to the nuclear receptor family and function as ligand-activated transcription factors. The name originated from early observations that certain compounds such as fibrates stimulate the growth and proliferation of peroxisomes (99). The receptor responsible for this effect was later identified and named PPAR $\alpha(39,50) . \operatorname{PPAR} \alpha$ is the principal activator/stimulator of peroxisomes. Renal PPAR $\alpha$ resides predominantly in the proximal tubule and corresponds to the highest density of peroxisomes in this part of the nephron (42).

In the proximal tubule, $\operatorname{PPAR} \alpha$ modulates fatty acid metabolism, oxidative stress, inflammatory response, and apoptosis. Normally, FFAs bound to plasma albumin are filtered through glomeruli, reabsorbed, and metabolized in proximal tubular cells. In the protein overload nephropathy model of AKI, repetitive injections of high amounts of albumin-bound fatty acids induce severe proximal tubular injury in PPAR $\alpha$ knockout mice, but not in wild-type mice (53). Tubular damage in PPAR $\alpha$ knockout mice is associated with accumulation of fatty acids, increased oxidative stress, and apoptosis. Even though the study did not specifically focus on 

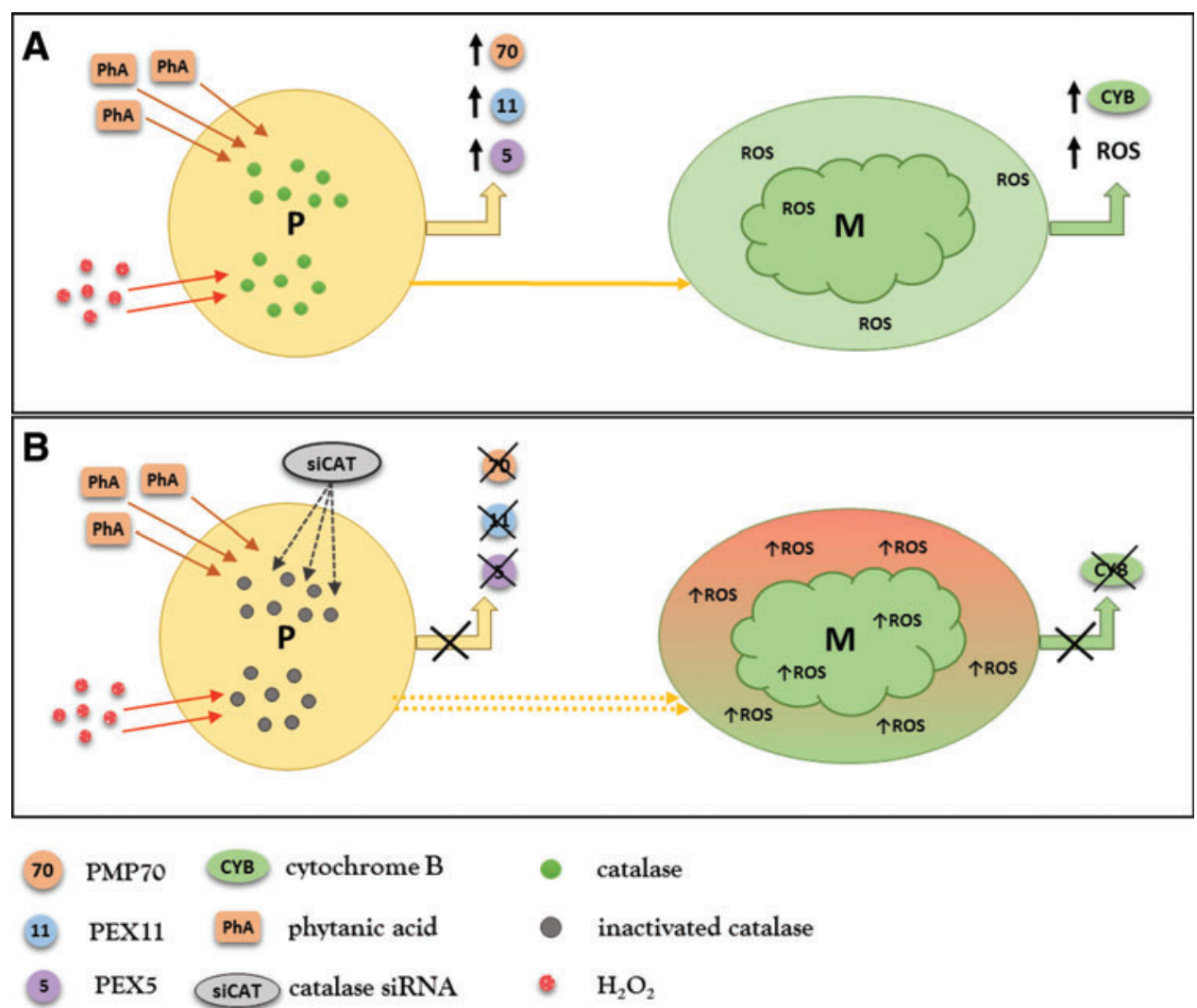

FIG. 7. Catalase deficiency impairs kidney peroxisomal and mitochondrial biogenesis. (A) Stimulation of mesangial cells with phytanic acid ( $\mathrm{PhA}$ ), which is exclusively metabolized by peroxisomes or with low concentrations of hydrogen peroxide $\left(\mathrm{H}_{2} \mathrm{O}_{2}\right)$, leads to upregulation of peroxisomal biogenesis markers, PEX5, PEX11a, and PMP70. The cells show a parallel increase of mitochondrial ROS (low activating concentration) accompanied by upregulation of the mitochondrial biogenesis marker, cytochrome B (CYB). (B) Mesangial cells transfected with catalase siRNA do not respond with upregulation of peroxisomal biogenesis markers (PEX5, PEX11a, PMP70) after stimulation with phytanic acid (PhA) or low concentrations of $\mathrm{H}_{2} \mathrm{O}_{2}$. Mitochondria of mesangial cells treated with catalase siRNA exhibit significantly higher levels of ROS and do not upregulate the expression of cytochrome B. It is implausible that perturbations in mitochondrial biogenesis/ homeostasis induced by dysfunctional peroxisomes are only a simple consequence of ROS diffusion from one organelle to another and almost certainly involve some form of (nowadays) unexplored interaction. ROS, reactive oxygen species. To see this illustration in color, the reader is referred to the web version of this article at www.liebertpub.com/ars

peroxisomes, the authors described an obvious damage of mitochondria characterized by swelling and rupture of the organelle (53).

Peroxin 11 (PEX11) is a small peroxin implicated in elongation and division of peroxisomes. PEX11 knockout mice have significantly lower numbers of functional peroxisomes. In the protein overload nephropathy model of AKI, PEX11 knockout mice show marked lipid infiltration of renal parenchyma and more severe tubulointerstitial injury compared with wild-type mice (106). PEX11 is a crucial regulator of peroxisomal proliferation and its deficiency impairs the biogenesis of peroxisomes. Similar to dysfunctional pexophagy, PEX11 deficiency negatively affects the regeneration of peroxisomes and aggravates renal injury.

$\operatorname{PPAR} \alpha$ knockout mice subjected to kidney ischemiareperfusion injury develop more extensive necrosis of the corticomedullary area and severe deterioration of renal function compared with wild-type littermates (81). Renal ischemia-reperfusion injury causes repression of PPAR $\alpha$ target genes, among them peroxisomal rate-limiting ACOX.
Treatment of normal rats with $\operatorname{PPAR} \alpha$ ligand, clofibrate, before the induction of renal ischemia reverses the inhibitory effect on FAO and significantly ameliorates acute tubular necrosis (81).

Cisplatin-induced nephrotoxicity is partially mediated by repression of ACOX and carnitine palmitoyl transferase (CPT) mRNA levels, the rate-limiting peroxisomal and mitochondrial FAO enzymes. The negative effect of cisplatin on FAO is delivered via inhibition of PPAR $\alpha$. Cisplatin decreases PPAR $\alpha$ binding ability to its target genes and does not affect PPAR $\alpha$ protein levels (80). Treatment with PPAR $\alpha$ ligand, WY14643, prevents the repression of mitochondrial FAO and ameliorates cisplatin-induced AKI. This protective effect of WY14643 is not present in PPAR $\alpha$ knockout mice. The authors also demonstrated that intact function of PPAR $\gamma$-coactivator-1 (PGC-1), a transcriptional coactivator of PPAR $\alpha$ and PPAR $\gamma$, further increases the survival rates of proximal tubular cells during cisplatin-induced AKI (62). Transgenic mice overexpressing $\operatorname{PPAR} \alpha$ in proximal tubules demonstrate improved renal function and morphology during 
cisplatin- and ischemia-induced AKI. Histopathological examination reveals a substantial reduction of tubular damage, particularly in the S3 segments typically affected in AKI. The protective effect of PPAR $\alpha$ overexpression in the proximal tubule is mediated mainly through improvement of fatty acid metabolism. PPAR $\alpha$-mediated nephroprotection does not require the presence of an exogenous PPAR $\alpha$ ligand, which emphasizes the essential role of PPAR $\alpha$ per se (61).

Fatty acid-binding proteins (FABPs) are members of a conserved multigene family involved in fatty acid transport from the plasma membrane to intracellular organelles, such as mitochondria and peroxisomes (15). L-FABP is an isoform expressed in the liver and in renal proximal tubules. Treatment with PPAR $\alpha$ agonist, fibrate, increases the number of peroxisomes and ameliorates renal damage in cisplatininduced AKI. L-FABP protein is increased in proximal tubules of fibrate-treated mice and upregulation of L-FABP depends on intact PPAR $\alpha$ signaling (74). Treatment of rat hepatocytes with fibrates increases the peroxisomal L-FABP concentration above the total cellular L-FABP levels, which indicates a more efficient translocation of L-FABP into peroxisomes during fibrate treatment. The induction of L-FABP in liver cells goes hand in hand with the induction of peroxisomal FAO (1). In renal ischemia-reperfusion injury, LFABP binds excessive FFAs and lipid peroxidation products in tubular cells and transports these into the tubular lumen (109). Several studies confirmed the ability of L-FABP to attenuate renal injury and demonstrated the potential of LFABP for use as a biomarker of kidney damage (107).

Transgenic mice overexpressing PPAR $\alpha$ in proximal tubules show decreased expression of inflammatory and profibrotic cytokines in a unilateral ureteral obstruction model of renal injury. The expression of fibrogenic genes, including collagen 1, $\alpha$-smooth muscle actin, and fibronectin, is significantly reduced. The peritubular fibrosis present in wildtype mice is almost absent in kidneys of PPAR $\alpha$ transgenic animals. These results indicate that PPAR $\alpha$ overexpression in the proximal tubule is able to reduce the extent of tubulointerstitial fibrosis after kidney injury (60).

Chau et al. investigated changes of microRNA expression in renal fibrosis and showed that microRNA-21 (miR-21) is highly elevated in experimental animal models and in human transplanted kidneys with nephropathy (14). Systemic deletion of miR-21 causes no apparent abnormality in mice. However, miR-21 knockout mice develop significantly less interstitial fibrosis in response to kidney injury. The investigators scrutinized genes silenced in response to kidney injury in miR-21 wild-type mice and compared them with miR-21 wild-type mice treated with anti-miR-21 oligonucleotides. Interestingly, the analysis of genes upregulated in the absence of miR-21 identified genes involved in peroxisomal (ACOX) and mitochondrial (CPT) FAO pathways regulated by PPAR $\alpha$. PPAR $\alpha$ deficiency abrogates the antifibrotic effect of anti-miR-21 oligonucleotides and indicates that PPAR $\alpha-$ controlled FAO pathways are the major targets of miR-21 in renal disease $(14,22)$.

These results underline the potential of PPAR $\alpha$-mediated modulation of FAO activity as a potential therapeutic strategy in AKI. One problem that needs to be mentioned is that human cells express significantly less PPAR $\alpha$ than rodent cells (31). Hence, the potential of PPAR expression and overexpression in human renal pathogenesis needs further demonstration.

SIRT1 is an NAD-dependent deacetylase that regulates numerous cellular functions and has been associated with longevity in mammals (7). Renal SIRT1 reduces apoptosis and inflammation and improves lipid metabolism, just to name a few. In proximal tubular cells, SIRT1 regulates $\mathrm{H}_{2} \mathrm{O}_{2}$ levels by modulating the expression of catalase in either a positive or a negative way, depending on the oxidative status of the cell. Under normal conditions, SIRT1 suppresses catalase and helps to maintain low hormetic levels of ROS, which participate in cell signaling and stimulate peroxisomal biogenesis. SIRT1 upregulation during increased oxidative stress reduces the apoptosis of renal tubular cells by stimulation of catalase synthesis that is mediated through deacetylation of forkhead transcription factor, forkhead box O3 (FOXO3), by SIRT1 (35). Transgenic mice with SIRT1 overexpression in proximal tubules show decreased levels of ROS and diminished tubular cell apoptosis during cisplatin-induced AKI. SIRT1 overexpression rescues proximal tubules from cisplatin-induced injury by maintaining peroxisome number and functions, in particular by upregulation of catalase. This study reveals that peroxisome is an important intracellular target organelle for SIRT1 (34). Protective effects of SIRT1 in acute and chronic renal injury have also been reported by our group (103).

\section{Conclusions}

Although the discovery of peroxisomes recently celebrated its 60th anniversary, the contribution of this spectacular organelle to the pathogenesis of common human diseases remains scarcely explored.

Peroxisomes can generate as well as scavenge ROS and are together with mitochondria essential players in tightly regulated redox homeostasis. Many peroxisomal tasks and particularly the FAO are functionally connected to mitochondrial pathways. Peroxisomal oxidases are unique in generating high amounts of $\mathrm{H}_{2} \mathrm{O}_{2}$ that is decomposed by the most prominent peroxisomal antioxidant enzyme catalase. Very low hormetic concentrations of $\mathrm{H}_{2} \mathrm{O}_{2}$ play a role in cell signaling. Overproduction or impaired degradation of $\mathrm{H}_{2} \mathrm{O}_{2}$ results in increase of peroxisomal membrane permeability and leakage of $\mathrm{H}_{2} \mathrm{O}_{2}$ and peroxisomal matrix components into the cytoplasm. Peroxisomal dysfunction induces alterations of mitochondrial membrane potential and promotes generation of mitochondrial ROS. Renal tubular cells rely on FAO as an essential source of ATP and alterations of this critical energygenerating pathway may aggravate kidney injury. Peroxisomes increase their metabolic activity and proliferation rates in response to stimuli acting through PPAR $\alpha$. Treatment with $\operatorname{PPAR} \alpha$ agonists such as fibrates preserves FAO and shows nephroprotective effects in AKI.

The evidence from studies on the physiology and pathophysiology of renal disorders is consistent in showing that neither peroxisomes nor mitochondria alone are involved, but rather the mitochondria-peroxisome partnership plays a major role.

Despite recent progress, further studies are needed to elucidate the molecular mechanisms induced by dysfunctional peroxisomes and the implications of the dysregulated mitochondriaperoxisome axis in the pathogenesis of renal injury. 


\section{References}

1. Antonenkov VD, Sormunen RT, Ohlmeier S, Amery L, Fransen M, Mannaerts GP, and Hiltunen JK. Localization of a portion of the liver isoform of fatty-acid-binding protein (L-FABP) to peroxisomes. Biochem J 394: 475484, 2006.

2. Baes M and Van Veldhoven PP. Mouse models for peroxisome biogenesis defects and beta-oxidation enzyme deficiencies. Biochim Biophys Acta 1822: 1489-1500, 2012.

3. Bagattin A, Hugendubler L, and Mueller E. Transcriptional coactivator PGC-1alpha promotes peroxisomal remodeling and biogenesis. Proc Natl Acad Sci U S A 107: 20376-20381, 2010.

4. Behrends $\mathrm{C}$ and Fulda S. Receptor proteins in selective autophagy. Int J Cell Biol 2012: 673290, 2012.

5. Bharti P, Schliebs W, Schievelbusch T, Neuhaus A, David C, Kock K, Herrmann C, Meyer HE, Wiese S, Warscheid B, Theiss C, and Erdmann R. PEX14 is required for microtubule-based peroxisome motility in human cells. $J$ Cell Sci 124: 1759-1768, 2011.

6. Bonekamp NA, Volkl A, Fahimi HD, and Schrader M. Reactive oxygen species and peroxisomes: struggling for balance. Biofactors 35: 346-355, 2009.

7. Borradaile NM and Pickering JG. NAD(+), sirtuins, and cardiovascular disease. Curr Pharm Des 15: 110-117, 2009.

8. Boti Z, Ivanyi B, Kobor J, and Ormos J. Histochemical studies on peroxisomes in regenerating proximal tubules of the kidney. Br J Exp Pathol 60: 620-626, 1979.

9. Braverman NE, D'Agostino MD, and Maclean GE. Peroxisome biogenesis disorders: biological, clinical and pathophysiological perspectives. Dev Disabil Res Rev 17: 187-196, 2013.

10. Brezniceanu ML, Liu F, Wei CC, Tran S, Sachetelli S, Zhang SL, Guo DF, Filep JG, Ingelfinger JR, and Chan JS. Catalase overexpression attenuates angiotensinogen expression and apoptosis in diabetic mice. Kidney Int 71: 912-923, 2007.

11. Brink SC and Danpure CJ. Protein import into peroxisomes: methods. eLS 2001 [Epub ahead of print]; DOI: 10.1038/npg.els.0002618.

12. Brown JM, Grosso MA, Terada LS, Whitman GJ, Banerjee A, White CW, Harken AH, and Repine JE. Endotoxin pretreatment increases endogenous myocardial catalase activity and decreases ischemia-reperfusion injury of isolated rat hearts. Proc Natl Acad Sci U S A 86: 2516-2520, 1989.

13. Charles Jennette J. Heptinstall's Pathology of the Kidney. Philadelphia: Lippincott Williams \& Wilkins, 2007.

14. Chau BN, Xin C, Hartner J, Ren S, Castano AP, Linn G, Li J, Tran PT, Kaimal V, Huang X, Chang AN, Li S, Kalra A, Grafals M, Portilla D, MacKenna DA, Orkin SH, and Duffield JS. MicroRNA-21 promotes fibrosis of the kidney by silencing metabolic pathways. Sci Transl Med 4: 121ra18, 2012.

15. Chen HM, Zheng CX, Gao Q, Ge YC, and Liu ZH. Hearttype fatty acid binding protein is associated with proteinuria in obesity. PLoS One 7: e45691, 2012.

16. De Duve C. The origin of eukaryotes: a reappraisal. Nat Rev Genet 8: 395-403, 2007.

17. De Duve $\mathrm{C}$ and Baudhuin P. Peroxisomes (microbodies and related particles). Physiol Rev 46: 323-357, 1966.

18. Dear JW, Kobayashi H, Jo SK, Holly MK, Hu X, Yuen PS, Brechbiel MW, and Star RA. Dendrimer-enhanced
MRI as a diagnostic and prognostic biomarker of sepsisinduced acute renal failure in aged mice. Kidney Int 67: 2159-2167, 2005.

19. Dhaunsi GS and Bitar MS. Antioxidants attenuate diabetes-induced activation of peroxisomal functions in the rat kidney. J Biomed Sci 11: 566-570, 2004.

20. Dhaunsi GS, Yousif MH, and Benter IF. FPTIII mitigates peroxisome-mediated oxidative stress in kidneys of spontaneously hypertensive diabetic rats. Kidney Blood Press Res 33: 60-65, 2010.

21. Dixit E, Boulant S, Zhang Y, Lee AS, Odendall C, Shum B, Hacohen N, Chen ZJ, Whelan SP, Fransen M, Nibert ML, Superti-Furga G, and Kagan JC. Peroxisomes are signaling platforms for antiviral innate immunity. Cell 141: 668-681, 2010.

22. Duffield JS, Grafals M, and Portilla D. MicroRNAs are potential therapeutic targets in fibrosing kidney disease: lessons from animal models. Drug Discov Today Dis Models 10: e127-e135, 2013.

23. Eadon MT, Hack BK, Xu C, Ko B, Toback FG, and Cunningham PN. Endotoxemia alters tight junction gene and protein expression in kidney. Am J Physiol Renal Physiol 303: F821-F830, 2012.

24. El-Achkar TM and Dagher PC. Tubular cross talk in acute kidney injury: a story of sense and sensibility. Am J Physiol Renal Physiol 308: F1317-F1323, 2015.

25. Feldkamp T, Kribben A, Roeser NF, Senter RA, and Weinberg JM. Accumulation of nonesterified fatty acids causes the sustained energetic deficit in kidney proximal tubules after hypoxia-reoxygenation. Am J Physiol Renal Physiol 290: F465-F477, 2006.

26. Ferdinandusse S, Finckh B, de Hingh YC, Stroomer LE, Denis S, Kohlschutter A, and Wanders RJ. Evidence for increased oxidative stress in peroxisomal D-bifunctional protein deficiency. Mol Genet Metab 79: 281-287, 2003.

27. Fransen M, Nordgren M, Wang B, Apanasets O, and Van Veldhoven PP. Aging, age-related diseases and peroxisomes. Subcell Biochem 69: 45-65, 2013.

28. Frederiks WM, Bosch KS, Hoeben KA, van Marle J, and Langbein S. Renal cell carcinoma and oxidative stress: the lack of peroxisomes. Acta Histochem 112: 364-371, 2010.

29. Frederiks WM, Vreeling-Sindelarova H, and Van Noorden CJ. Loss of peroxisomes causes oxygen insensitivity of the histochemical assay of glucose-6-phosphate dehydrogenase activity to detect cancer cells. J Histochem Cytochem 55: 175-181, 2007.

30. Gabaldon T. Peroxisome diversity and evolution. Philos Trans R Soc Lond B Biol Sci 365: 765-773, 2010.

31. Guan Y, Zhang Y, Davis L, and Breyer MD. Expression of peroxisome proliferator-activated receptors in urinary tract of rabbits and humans. Am J Physiol 273: F1013F1022, 1997.

32. Gulati S, Ainol L, Orak J, Singh AK, and Singh I. Alterations of peroxisomal function in ischemia-reperfusion injury of rat kidney. Biochim Biophys Acta 1182: 291298, 1993.

33. Gulati S, Singh AK, Irazu C, Orak J, Rajagopalan PR, Fitts CT, and Singh I. Ischemia-reperfusion injury: biochemical alterations in peroxisomes of rat kidney. Arch Biochem Biophys 295: 90-100, 1992.

34. Hasegawa K, Wakino S, Yoshioka K, Tatematsu S, Hara Y, Minakuchi H, Sueyasu K, Washida N, Tokuyama H, Tzukerman M, Skorecki K, Hayashi K, and Itoh $\mathrm{H}$. Kidney-specific overexpression of Sirt1 protects against 
acute kidney injury by retaining peroxisome function. $J$ Biol Chem 285: 13045-13056, 2010.

35. Hasegawa K, Wakino S, Yoshioka K, Tatematsu S, Hara Y, Minakuchi H, Washida N, Tokuyama H, Hayashi K, and Itoh $\mathrm{H}$. Sirt1 protects against oxidative stress-induced renal tubular cell apoptosis by the bidirectional regulation of catalase expression. Biochem Biophys Res Commun 372: 51-56, 2008.

36. Hashimoto T. Individual peroxisomal beta-oxidation enzymes. Ann N Y Acad Sci 386: 5-12, 1982.

37. Hashimoto T. Peroxisomal beta-oxidation: enzymology and molecular biology. Ann N Y Acad Sci 804: 86-98, 1996.

38. Hervouet $\mathrm{E}$ and Godinot C. Mitochondrial disorders in renal tumors. Mitochondrion 6: 105-117, 2006.

39. Hess R, Staubli W, and Riess W. Nature of the hepatomegalic effect produced by ethyl-chlorophenoxyisobutyrate in the rat. Nature 208: 856-858, 1965.

40. Hsiao HW, Tsai KL, Wang LF, Chen YH, Chiang PC, Chuang SM, and Hsu C. The decline of autophagy contributes to proximal tubular dysfunction during sepsis. Shock 37: 289-296, 2012.

41. Hsieh TJ, Zhang SL, Filep JG, Tang SS, Ingelfinger JR, and Chan JS. High glucose stimulates angiotensinogen gene expression via reactive oxygen species generation in rat kidney proximal tubular cells. Endocrinology 143: 2975-2985, 2002.

42. Huang Q, Yeldandi A, Alvares K, Ide H, Reddy J, and Rao M. Localization of peroxisome proliferator-activated receptor in mouse and rat-tissues and demonstration of its nuclear translocation in transfected cv-1 cells. Int J Oncol 6: 307-312, 1995.

43. Hunt MC and Alexson SE. Novel functions of acyl-CoA thioesterases and acyltransferases as auxiliary enzymes in peroxisomal lipid metabolism. Prog Lipid Res 47: 405$421,2008$.

44. Huybrechts SJ, Van Veldhoven PP, Brees C, Mannaerts GP, Los GV, and Fransen M. Peroxisome dynamics in cultured mammalian cells. Traffic 10: 1722-1733, 2009.

45. Hwang I, Lee J, Huh JY, Park J, Lee HB, Ho YS, and Ha $\mathrm{H}$. Catalase deficiency accelerates diabetic renal injury through peroxisomal dysfunction. Diabetes 61: 728-738, 2012.

46. Ibrahim IY, Elbassuoni EA, Ragy MM, and Habeeb WN. Gender difference in the development of cardiac lesions following acute ischemic-reperfusion renal injury in albino rats. Gen Physiol Biophys 32: 421-428, 2013.

47. Imanaka T, Aihara K, Suzuki Y, Yokota S, and Osumi T. The 70-kDa peroxisomal membrane protein (PMP70), an ATP-binding cassette transporter. Cell Biochem Biophys 32 Spring: 131-138, 2000.

48. Inestrosa NC, Carvajal FJ, Zolezzi JM, Tapia-Rojas C, Serrano F, Karmelic D, Toledo EM, Toro A, Toro J, and Santos MJ. Peroxisome proliferators reduce spatial memory impairment, synaptic failure, and neurodegeneration in brains of a double transgenic mice model of Alzheimer's disease. J Alzheimers Dis 33: 941-959, 2013.

49. Islinger M, Grille S, Fahimi HD, and Schrader M. The peroxisome: an update on mysteries. Histochem Cell Biol 137: 547-574, 2012.

50. Issemann I and Green S. Activation of a member of the steroid hormone receptor superfamily by peroxisome proliferators. Nature 347: 645-650, 1990.

51. Ivashchenko O, Van Veldhoven PP, Brees C, Ho YS, Terlecky SR, and Fransen M. Intraperoxisomal redox balance in mammalian cells: oxidative stress and interorganellar cross-talk. Mol Biol Cell 22: 1440-1451, 2011.

52. Kalakeche R, Hato T, Rhodes G, Dunn KW, El-Achkar TM, Plotkin Z, Sandoval RM, and Dagher PC. Endotoxin uptake by $\mathrm{S} 1$ proximal tubular segment causes oxidative stress in the downstream S2 segment. J Am Soc Nephrol 22: 1505-1516, 2011.

53. Kamijo Y, Hora K, Kono K, Takahashi K, Higuchi M, Ehara T, Kiyosawa K, Shigematsu H, Gonzalez FJ, and Aoyama T. PPARalpha protects proximal tubular cells from acute fatty acid toxicity. J Am Soc Nephrol 18: 30893100, 2007.

54. Kang YJ, Chen Y, and Epstein PN. Suppression of doxorubicin cardiotoxicity by overexpression of catalase in the heart of transgenic mice. J Biol Chem 271: 1261012616, 1996.

55. Kim PK, Hailey DW, Mullen RT, and LippincottSchwartz J. Ubiquitin signals autophagic degradation of cytosolic proteins and peroxisomes. Proc Natl Acad Sci U S A 105: 20567-20574, 2008.

56. Koepke JI, Nakrieko KA, Wood CS, Boucher KK, Terlecky LJ, Walton PA, and Terlecky SR. Restoration of peroxisomal catalase import in a model of human cellular aging. Traffic 8: 1590-1600, 2007.

57. Lazarow PB and Fujiki Y. Biogenesis of peroxisomes. Annu Rev Cell Biol 1: 489-530, 1985.

58. Le Hir M and Dubach UC. Peroxisomal and mitochondrial beta-oxidation in the rat kidney: distribution of fatty acylcoenzyme A oxidase and 3-hydroxyacyl-coenzyme A dehydrogenase activities along the nephron. $J$ Histochem Cytochem 30: 441-444, 1982.

59. Lee SS, Pineau T, Drago J, Lee EJ, Owens JW, Kroetz DL, Fernandez-Salguero PM, Westphal $\mathrm{H}$, and Gonzalez FJ. Targeted disruption of the alpha isoform of the peroxisome proliferator-activated receptor gene in mice results in abolishment of the pleiotropic effects of peroxisome proliferators. Mol Cell Biol 15: 3012-3022, 1995.

60. Li S, Mariappan N, Megyesi J, Shank B, Kannan K, Theus S, Price PM, Duffield JS, and Portilla D. Proximal tubule PPARalpha attenuates renal fibrosis and inflammation caused by unilateral ureteral obstruction. Am J Physiol Renal Physiol 305: F618-F627, 2013.

61. Li S, Nagothu KK, Desai V, Lee T, Branham W, Moland C, Megyesi JK, Crew MD, and Portilla D. Transgenic expression of proximal tubule peroxisome proliferatoractivated receptor-alpha in mice confers protection during acute kidney injury. Kidney Int 76: 1049-1062, 2009.

62. Li S, Wu P, Yarlagadda P, Vadjunec NM, Proia AD, Harris RA, and Portilla D. PPAR alpha ligand protects during cisplatin-induced acute renal failure by preventing inhibition of renal FAO and PDC activity. Am J Physiol Renal Physiol 286: F572-F580, 2004.

63. Lieberthal $\mathrm{W}$ and Nigam SK. Acute renal failure. I. Relative importance of proximal vs. distal tubular injury. Am J Physiol 275: F623-F631, 1998.

64. Litwin JA, Volkl A, Muller-Hocker J, and Fahimi HD. Immunocytochemical demonstration of peroxisomal enzymes in human kidney biopsies. Virchows Arch B Cell Pathol Incl Mol Pathol 54: 207-213, 1988.

65. Litwin JA, Volkl A, Stachura J, and Fahimi HD. Detection of peroxisomes in human liver and kidney fixed with formalin and embedded in paraffin: the use of catalase and lipid beta-oxidation enzymes as immunocytochemical markers. Histochem J 20: 165-173, 1988. 
66. Lopez-Hernandez FJ and Lopez-Novoa JM. Potential utility of PPARalpha activation in the prevention of ischemic and drug-induced acute renal damage. Kidney Int 76: 1022-1024, 2009.

67. Ma C, Agrawal G, and Subramani S. Peroxisome assembly: matrix and membrane protein biogenesis. J Cell Biol 193: 7-16, 2011.

68. Ma C, Schumann U, Rayapuram N, and Subramani S. The peroxisomal matrix import of Pex8p requires only PTS receptors and Pex14p. Mol Biol Cell 20: 3680-3689, 2009.

69. Mannaerts GP and Van Veldhoven PP. [Peroxisomal betaoxidation]. Verh K Acad Geneeskd Belg 55: 45-78, 1993.

70. Masters CJ. Cellular signalling: the role of the peroxisome. Cell Signal 8: 197-208, 1996.

71. McIntyre CW, Harrison LE, Eldehni MT, Jefferies HJ, Szeto CC, John SG, Sigrist MK, Burton JO, Hothi D, Korsheed S, Owen PJ, Lai KB, and Li PK. Circulating endotoxemia: a novel factor in systemic inflammation and cardiovascular disease in chronic kidney disease. Clin J Am Soc Nephrol 6: 133-141, 2011.

72. Mizushima N and Komatsu M. Autophagy: renovation of cells and tissues. Cell 147: 728-741, 2011.

73. Morita $\mathrm{M}$ and Imanaka T. Peroxisomal ABC transporters: structure, function and role in disease. Biochim Biophys Acta 1822: 1387-1396, 2012.

74. Negishi K, Noiri E, Sugaya T, Li S, Megyesi J, Nagothu $\mathrm{K}$, and Portilla D. A role of liver fatty acid-binding protein in cisplatin-induced acute renal failure. Kidney Int 72 : 348-358, 2007.

75. Nuttall JM, Motley A, and Hettema EH. Peroxisome biogenesis: recent advances. Curr Opin Cell Biol 23: 421426, 2011.

76. Odendall $\mathrm{C}$ and Kagan JC. Peroxisomes and the antiviral responses of mammalian cells. Subcell Biochem 69: 6775, 2013.

77. Platta HW and Erdmann R. Peroxisomal dynamics. Trends Cell Biol 17: 474-484, 2007.

78. Platta HW and Erdmann R. The peroxisomal protein import machinery. FEBS Lett 581: 2811-2819, 2007.

79. Portilla D. Role of fatty acid beta-oxidation and calciumindependent phospholipase A2 in ischemic acute renal failure. Curr Opin Nephrol Hypertens 8: 473-477, 1999.

80. Portilla D, Dai G, McClure T, Bates L, Kurten R, Megyesi $\mathrm{J}$, Price P, and Li S. Alterations of PPARalpha and its coactivator PGC-1 in cisplatin-induced acute renal failure. Kidney Int 62: 1208-1218, 2002.

81. Portilla D, Dai G, Peters JM, Gonzalez FJ, Crew MD, and Proia AD. Etomoxir-induced PPARalpha-modulated enzymes protect during acute renal failure. Am J Physiol Renal Physiol 278: F667-F675, 2000.

82. Purdue PE and Lazarow PB. Peroxisome biogenesis. Annu Rev Cell Dev Biol 17: 701-752, 2001.

83. Reddy JK and Hashimoto T. Peroxisomal beta-oxidation and peroxisome proliferator-activated receptor alpha: an adaptive metabolic system. Аnnu Rev Nutr 21: 193-230, 2001.

84. Reimer DL, Bailley J, and Singh SM. Complete cDNA and $5^{\prime}$ genomic sequences and multilevel regulation of the mouse catalase gene. Genomics 21: 325-336, 1994.

85. Rhodin J. Correlation of ultrastructural organization and function in normal experimentally changed convoluted tubule cells of the mouse kidney. Thesis. Karolinska Institutet, Stockholm, 1954.
86. Rivera-Zavala JB, Baez-Ruiz A, and Diaz-Munoz M. Changes in the $24 \mathrm{~h}$ rhythmicity of liver PPARs and peroxisomal markers when feeding is restricted to two daytime hours. PPAR Res 2011: 261584, 2011.

87. Rottensteiner H, Kramer A, Lorenzen S, Stein K, Landgraf C, Volkmer-Engert R, and Erdmann R. Peroxisomal membrane proteins contain common Pex19p-binding sites that are an integral part of their targeting signals. Mol Biol Cell 15: 3406-3417, 2004.

88. Rucktäschel R, Girzalsky W, and Erdmann R. Protein import machineries of peroxisomes. Biochim Biophys Acta 1808: 892-900, 2011.

89. Ruidera E, Irazu CE, Rajagopalan PR, Orak JK, Fitts CT, and Singh I. Fatty acid metabolism in renal ischemia. Lipids 23: 882-884, 1988.

90. Scherz-Shouval R, Shvets E, Fass E, Shorer H, Gil L, and Elazar Z. Reactive oxygen species are essential for autophagy and specifically regulate the activity of Atg4. EMBO J 26: 1749-1760, 2007.

91. Schluter A, Fourcade S, Ripp R, Mandel JL, Poch O, and Pujol A. The evolutionary origin of peroxisomes: an ERperoxisome connection. Mol Biol Evol 23: 838-845, 2006.

92. Schrader M, Bonekamp NA, and Islinger M. Fission and proliferation of peroxisomes. Biochim Biophys Acta 1822: 1343-1357, 2012.

93. Sigfrid LA, Cunningham JM, Beeharry N, Lortz S, Tiedge M, Lenzen S, Carlsson C, and Green IC. Cytokines and nitric oxide inhibit the enzyme activity of catalase but not its protein or mRNA expression in insulin-producing cells. J Mol Endocrinol 31: 509-518, 2003.

94. Smith JJ and Aitchison JD. Peroxisomes take shape. Nat Rev Mol Cell Biol 14: 803-817, 2013.

95. Stolz DB, Zamora R, Vodovotz Y, Loughran PA, Billiar TR, Kim YM, Simmons RL, and Watkins SC. Peroxisomal localization of inducible nitric oxide synthase in hepatocytes. Hepatology 36: 81-93, 2002.

96. Szeto CC, Kwan BC, Chow KM, Lai KB, Chung KY, Leung $\mathrm{CB}$, and Li PK. Endotoxemia is related to systemic inflammation and atherosclerosis in peritoneal dialysis patients. Clin J Am Soc Nephrol 3: 431-436, 2008.

97. Till A, Lakhani R, Burnett SF, and Subramani S. Pexophagy: the selective degradation of peroxisomes. Int $J$ Cell Biol 2012: 512721, 2012.

98. Todde V, Veenhuis M, and van der Klei IJ. Autophagy: principles and significance in health and disease. Biochim Biophys Acta 1792: 3-13, 2009.

99. Touyz RM and Schiffrin EL. Peroxisome proliferatoractivated receptors in vascular biology-molecular mechanisms and clinical implications. Vascul Pharmacol 45: 19-28, 2006.

100. Van Veldhoven PP and Baes M. Peroxisome deficient invertebrate and vertebrate animal models. Front Physiol 4: 335, 2013.

101. Vasko R, Koziolek M, Ikehata M, Rastaldi MP, Jung K, Schmid H, Kretzler M, Muller GA, and Strutz F. Role of basic fibroblast growth factor (FGF-2) in diabetic nephropathy and mechanisms of its induction by hyperglycemia in human renal fibroblasts. Am J Physiol Renal Physiol 296: F1452-F1463, 2009.

102. Vasko R, Ratliff BB, Bohr S, Nadel E, Chen J, Xavier S, Chander P, and Goligorsky MS. Endothelial peroxisomal dysfunction and impaired pexophagy promotes oxidative damage in lipopolysaccharide-induced acute kidney injury. Antioxid Redox Signal 19: 211-230, 2013. 
103. Vasko R, Xavier S, Chen J, Lin CH, Ratliff B, Rabadi M, Maizel J, Tanokuchi R, Zhang F, Cao J, and Goligorsky MS. Endothelial sirtuin 1 deficiency perpetrates nephrosclerosis through downregulation of matrix metalloproteinase-14: relevance to fibrosis of vascular senescence. J Am Soc Nephrol 25: 276-291, 2014.

104. Wanders RJ, Visser WF, van Roermund CW, Kemp S, and Waterham HR. The peroxisomal ABC transporter family. Pflugers Arch 453: 719-734, 2007.

105. Weinberg JM, Venkatachalam MA, Roeser NF, Saikumar P, Dong Z, Senter RA, and Nissim I. Anaerobic and aerobic pathways for salvage of proximal tubules from hypoxia-induced mitochondrial injury. Am J Physiol Renal Physiol 279: F927-F943, 2000.

106. Weng H, Ji X, Endo K, and Iwai N. Pex11a deficiency is associated with a reduced abundance of functional peroxisomes and aggravated renal interstitial lesions. Hypertension 64: 1054-1060, 2014.

107. Xu Y, Xie Y, Shao X, Ni Z, and Mou S. L-FABP: a novel biomarker of kidney disease. Clin Chim Acta 445: 85-90, 2015.

108. Yakunin E, Moser A, Loeb V, Saada A, Faust P, Crane DI, Baes M, and Sharon R. alpha-Synuclein abnormalities in mouse models of peroxisome biogenesis disorders. $J$ Neurosci Res 88: 866-876, 2010.

109. Yamamoto T, Noiri E, Ono Y, Doi K, Negishi K, Kamijo A, Kimura K, Fujita T, Kinukawa T, Taniguchi H, Nakamura K, Goto M, Shinozaki N, Ohshima S, and Sugaya T. Renal L-type fatty acid-binding protein in acute ischemic injury. J Am Soc Nephrol 18: 2894-2902, 2007.

110. Yokota S and Dariush Fahimi H. Degradation of excess peroxisomes in mammalian liver cells by autophagy and other mechanisms. Histochem Cell Biol 131: 455-458, 2009.

111. Yokota S, Oda T, and Fahimi HD. The role of 15lipoxygenase in disruption of the peroxisomal membrane and in programmed degradation of peroxisomes in normal rat liver. J Histochem Cytochem 49: 613-622, 2001.

112. Zmijewski JW, Lorne E, Zhao X, Tsuruta Y, Sha Y, Liu $\mathrm{G}$, and Abraham E. Antiinflammatory effects of hydrogen peroxide in neutrophil activation and acute lung injury. Am J Respir Crit Care Med 179: 694-704, 2009.

Address correspondence to: Dr. Radovan Vasko Department of Nephrology and Rheumatology University Medical Center Göttingen Robert-Koch-Str. 40 Göttingen 37075 Germany

E-mail:vaskorad@gmail.com
Date of first submission to ARS Central, February 8, 2016; date of final revised submission, March 7, 2016; date of acceptance, March 10, 2016.

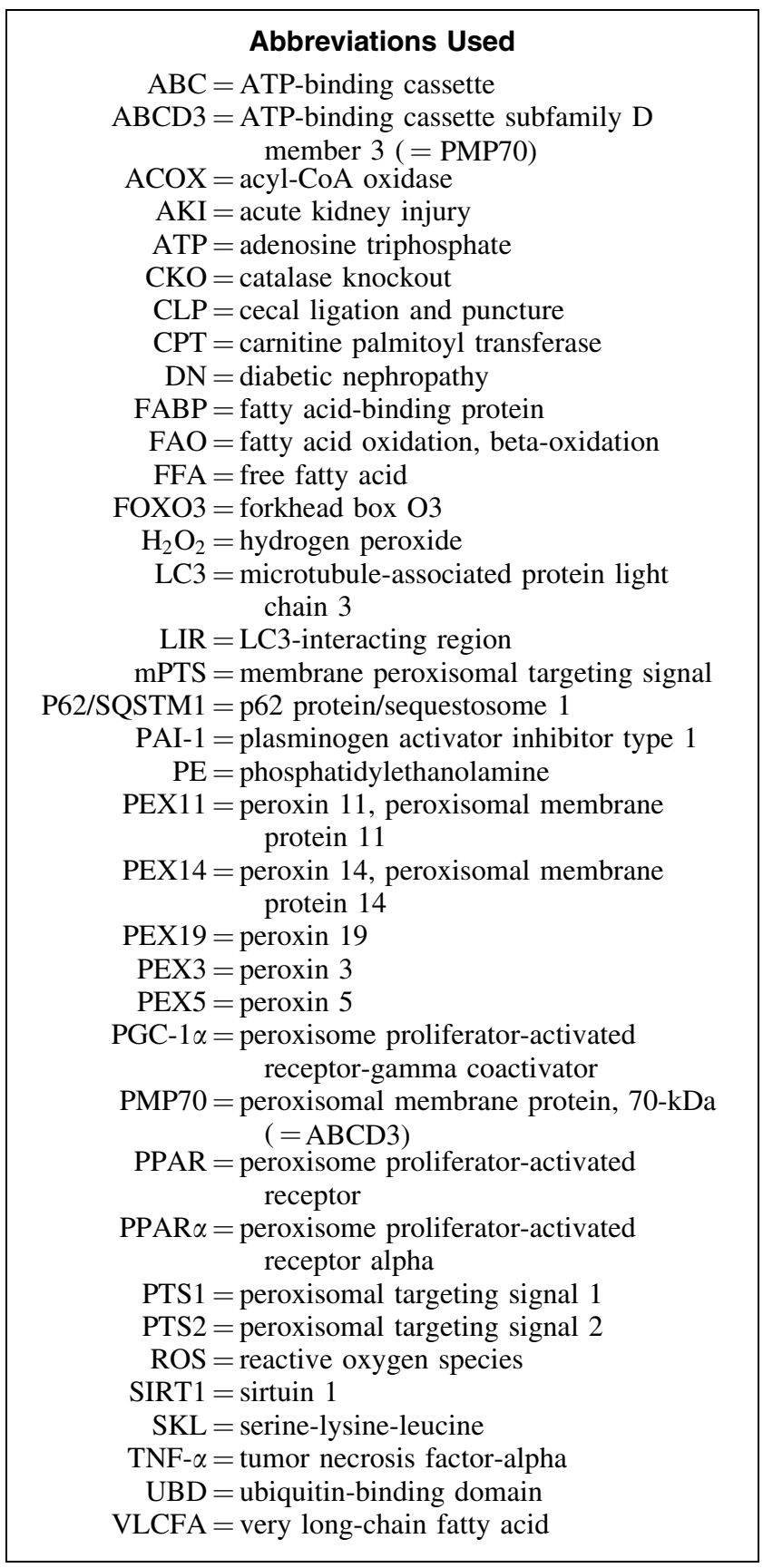

